\title{
Optical properties of zinc borotellurite glass doped with trivalent dysprosium ion
}

\begin{abstract}
The zinc borotellurite doped with dysprosium oxide glass samples with chemical formula $\{[(\mathrm{TeO} 2) 0.7(\mathrm{~B} 2 \mathrm{O} 3) 0.3] 0.7(\mathrm{ZnO}) 0.3\} 1-\mathrm{x}(\mathrm{Dy} 2 \mathrm{O} 3) \mathrm{x}$ (where $\mathrm{x}=0.01,0.02,0.03,0.04$ and $0.05 \mathrm{M}$ fraction) were prepared by using conventional melt quenching technique. The structural and optical properties of the proposed glass systems were characterized by using Xray diffraction (XRD) spectroscopy, Fourier Transform Infrared (FTIR) spectroscopy, and UV-VIS spectroscopy. The amorphous nature of the glass systems is confirmed by using XRD technique. The infrared spectra of the glass systems indicate three obvious absorption bands which are assigned to $\mathrm{BO}_{3}$ and $\mathrm{TeO}_{4}$ vibrational groups. Based on the absorption spectra obtained, the direct and indirect optical band gaps, as well as the Urbach energy were calculated. It is observed that both the direct and indirect optical band gaps increase with the concentration of $\mathrm{Dy}^{3+}$ ions. On the other hand, the Urbach energy is observed to decrease as the concentration of $\mathrm{Dy}^{3+}$ ions increases.
\end{abstract}

Keyword: Zinc borotellurite glass; Trivalent lanthanide; Dysprosium oxide; Optical properties; Optical band gap; Urbach energy 